\section{PRESIDENTIAL PROFILE 2009}

Prof. P. Gunasekaran, Chairperson, School of Biological Sciences, Madurai Kamaraj University, Madurai, is one of the pioneering Industrial Microbiologists in India. He has made significant contributions in Zymomonas mobilis genetics and ethanol fermentation technology. He has cloned and sequenced several genes from $Z$. mobilis and manipulated the $Z$. mobilis genome for efficient ethanol production. In addition, he has made significant contributions in process optimization and production of various industrial enzymes and antimicrobial agents from different bacterial and fungal sources. He has published more than 120 research papers in internationally reputed journals and presented more than 125 invited lectures at various international and national conferences.

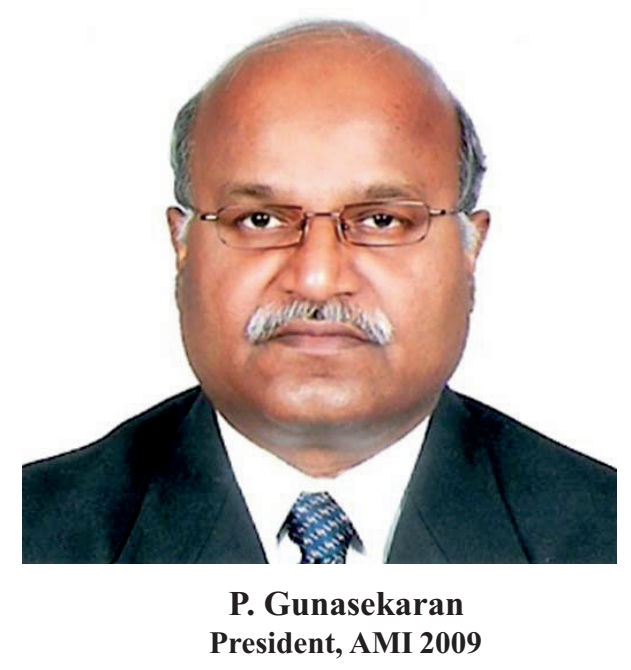

Dr. P. Gunasekaran is a Fellow of the National Academy of Biological Sciences (FNABS), Association of Microbiologists of India (FAMI) and Biotechnology Research Society of India (FBRS). He has received several national and international awards such as Life Time Achievement Award from Indian Association of Applied Microbiologists (2009), American Society of Microbiology International (ASM Indo-US) Professorship (2007), AMI-Prof.S.R.Vyas Award (2006), Tamil Nadu Scientist Award (1999), Louis Pasteur Award (1998), Patrimonial excelencia Nivel II fellowship, México (1996), etc. Currently, he is chairing the School of Biological Sciences and coordinating the Centre for Excellence in Genomic Sciences (CEGS) and UGC-Networking Resource Centre in Biological Sciences (UGC-NRCBS) at Madurai Kamaraj University, Madurai. 